\title{
Optimization of the nutritional composition of the food mixture, taking into account the individual restrictions of consumers
}

\author{
Mariya Klokonos*, Valery Karpov, Igor Nikitin, Olga Orlovtseva and Nataliya Ivanova \\ K.G. Razumovsky Moscow State University of technologies and management \\ (The First Cossack University), St. Zemlyanoy Val, 73, Moscow, Russian Federation
}

\begin{abstract}
The paper considers the problem of optimizing the composition of food mixtures intended for feeding individuals with a predisposition to diseases associated with impaired bone mineral density (BMD) by selecting the ratio of the main and additional raw materials in the mixture. The mathematical formulation of the problem was carried out and the result of its solution was obtained using a computer program. The formation of the optimal composition of the mixture was calculated taking into account two criteria - restrictions on the ratio of the main and additional raw materials and taking into account the specified requirements of the standard for the amount of basic nutrients that will provide nutritional support for people with a predisposition to BMD impairment.
\end{abstract}

\section{Introduction}

New trends related to digitalization, personalization and globalization of society are rapidly making a significant contribution to the daily life of a person. Global changes are also taking place in the field of food production, as well as providing society with food products, which are aimed not only at changing the basic characteristics of food products, but also at improving their digestibility and balance of the composition, provided for the individual needs of certain groups of citizens [1, 2, 3, 4].

At the intersection of sciences such as dietetics and genetics, two new scientific trends have emerged - nutrigenetics, which studies the effect of the genotype on the process of the onset and development of diseases associated with metabolism, and nutrigenomics, which studies the relationship between human nutrition and the characteristic features of its genome, which determines the effect of food on gene expression, and ultimately on human health $[5,6]$.

Following the basic approaches of nutrigenetics, several important conclusions can be drawn:

- to reduce the risks of diseases associated with impaired metabolic reactions in the body, correctly selected ratios of nutrients or their combination in the composition of the product can be effective;

\footnotetext{
* Corresponding author: m.klokonos@ mgutm.ru
} 
- by introducing positive expressing nutrients into the diet, it is possible to help a person to realize their potential to a greater extent, to stop or completely prevent the appearance of alimentary-dependent diseases [7,8].

Diseases identified by genetic tests include diseases associated with impaired bone metabolism. To date, a number of nutrients have been identified that are involved in the exchange of human bone tissue, the main ones among which are calcium and vitamin $\mathrm{D}$. Along with these nutrients, there is a lack of vitamins such as C, K, B6, B12, and trace elements: zinc, manganese, boron, silicon, selenium, magnesium, copper, which are associated with impaired bone metabolism and a decrease in bone mass. Therefore, having a hereditary predisposition to impaired bone metabolism, it is necessary to follow a special diet that ensures the intake of the above mentioned nutrients in sufficient quantities.

The food market, especially in metropolitan areas, is represented by a wide range of products for healthy nutrition. However, it is not always possible for specific groups of products to satisfy the needs of a person with dietary restrictions, for example, based on a genetic predisposition to the development of diseases. At the same time, the development of modern technologies allows us to talk about the «design» of food products with desired properties.

Over the past decade, companies producing fast food products, which are often characterized by low nutritional value, have been actively developing, which determines the relevance of a large number of scientific studies aimed at improving their composition. Fast food products also include products in the form of powdered or dry food mixtures, which must be diluted with water, milk or juice before consumption, in the proportions recommended by the manufacturer. It is worth noting that despite the simplicity of preparing such products, the developers recommend using such products only in the diets of people without health problems.

Therefore, the development of personalized food products in the form of fast food products for people with various types of genetic predispositions is urgent. When developing food products that contribute to the reduction or prevention of diseases associated with a violation of $\mathrm{BMD}$, it is necessary to follow the requirements for the ratio of characteristic nutrients in the composition of the designed product.

\section{Material and methods}

The task was to design a recipe for a personalized food mixture, as close as possible to the reference ratio of nutrients, and to determine the optimization criterion based on the ratio of the amount in the recipe for the mixture of the main and additional raw materials, provided their proportional composition is $88 \%$ : $12 \%$.

Based on the task, the initial data for its solution are: the reference composition of the food mixture, based on the norms of physiological needs for basic substances and energy, literature data of Russian and foreign scientists on the prevention of osteoporosis; vector of quality indicators of the mixture, $i$ - is the ratio of the main raw materials; $j$ - is the amount of nutrients in $100 \mathrm{~g}$ of raw materials; $k$ - is the ratio of additional raw materials; $I$ - is a variant of the blend of the mixture and $\operatorname{ingr}(i, j)$ - is an indicator of the quality of the ingredient.

\section{Results and discussion}

To solve the problem, an expression was used that determines the required set of ingredients based on the availability of specific nutrients in the mixture [7]: 


$$
\operatorname{Ingr}(i)=<\operatorname{ingr}(i, j), i=1, N, j=1, M
$$

where $\operatorname{ingr}(i, j)$ - is the quality index $j$ of ingredient $i$.

$(j=1$ - protein content in 100 grams, g;

$j=2$ - fat content in 100 grams, g;

$j=3$ - content of vitamin $\mathrm{C}$ in 100 grams, $\mathrm{g}$;

$j=4$ - content of vitamin $\mathrm{D}_{3}$ in 100 grams, g;

$j=5$ - calcium content in 100 grams, $\mathrm{g}$;

$j=6$ - silicon content in 100 grams, g;

$j=7$ - magnesium content in 100 grams, g;

$j=8$ - phosphorus content in 100 grams, g;

$j=9$ - zinc content in 100 grams, g;

$j=10$ - manganese content in 100 grams, g;

$j=11$ - copper content in 100 grams, g;

$j=12$ - selenium content in 100 grams, g;

$j=13$ - potassium content in 100 grams, g;

$j=14$ - iron content in 100 grams, g;

$j=15$ - content of vitamin $\mathrm{B}_{6}$ in 100 grams, $\mathrm{g}$;

$j=16$ - the content of vitamin $\mathrm{B}_{12}$ in 100 grams, g).

Then the set of additional ingredients will be calculated according to the expression:

$$
\operatorname{Dob}(k)=<\operatorname{dob}(k, j)>, k=1, K, j=1, M
$$

where $\operatorname{dob}(k, j)$ - is the quality index $j$ of the additive $k$.

Determination of the vector of the standard of quality indicators of the mixture of ingredients and additives was determined according to:

$$
E t=<\operatorname{et}(j)>, j=1, M
$$

where $e t(j)$ - is the quality index $j$ of the reference blend.

It will be necessary to define two vectors $\operatorname{Vingr}=\langle\operatorname{vingr}(i)\rangle$ and $\operatorname{Vdob}=<$ $\operatorname{vdob}(k)>$, where vingr $(i)$ - is the content of the $i$-th ingredient in the blend of the mixture, $\%, v d o b(k)$ - content of the $k$-th additive in the blend of the mixture, $\%$.

Then the quality indicators of the 1-th mixture $(\operatorname{Kkup}(l)=\langle k k u p(l, j>))$ will be determined according to the condition:

$$
\operatorname{kkup}(l, j)=\sum_{i=1}^{N} \operatorname{vingr}(l, i) * \operatorname{ingr}(i, j) / 100+\sum_{k=1}^{K} \operatorname{vdob}(l, k) * \operatorname{dob}(k, j) / 100
$$

where $k k u p(l, j)$ - is the quality indicator $j$ of the blend $l$,

$\operatorname{vingr}(l, i)$ - the content of the $i$-th ingredient in the $l$-th variant of the blend,

$\operatorname{ingr}(i, j)$ - value of the $j$-th quality indicator of the $i$-th ingredient.

$v \operatorname{dob}(l, k)$ - the content of the $k$-th additive in the $l$-th variant of the blend,

$\operatorname{dob}(k, j)-$ is the value of the $j$-th quality indicator of the $k$-th additive.

The vectors Vingr and $V d o b$ were designated as an admissible solution to the problem, which satisfy the following constraints (5-8). 
Limitations:

$$
\begin{gathered}
\forall l \sum_{i=1}^{N} \operatorname{vingr}(l, i)=s 1 \\
\forall l \sum_{k=1}^{K} \operatorname{dob}(l, k)=s 2 \\
s 1+s 2=100 \\
\forall l \forall i(\operatorname{vingr}(l, i) \in m N) \\
\forall l \forall k(\operatorname{dob}(l, k) \in m N)
\end{gathered}
$$

where $s 1, s 2$ are the given percentages of the main ingredients and additives, respectively; $m N-$ is the set of natural numbers.

An optimal solution to a problem is a feasible solution that minimizes the criterion $Q$ presented below (9).

$$
\text { Optimization criterion: }
$$

$$
Q(l)=\sum_{j \in J(l)}((e t(l, j)-k k u p(l, j)) / e t(l, j))^{2}
$$

where $J(l)=E\{j \mid \operatorname{et}(l, j)-k k u p(l, j)>0\}$

The optimal value of the Qopt criterion is determined by such $l$ for which $Q$ is minimal:

$$
Q o p t=\min Q o p t=\min _{l} Q(l)
$$

The program window with data on solving the problem is shown in Figures 1 and 2.



Fig. 1. Interface and result of solving the optimization problem for the main raw material. 


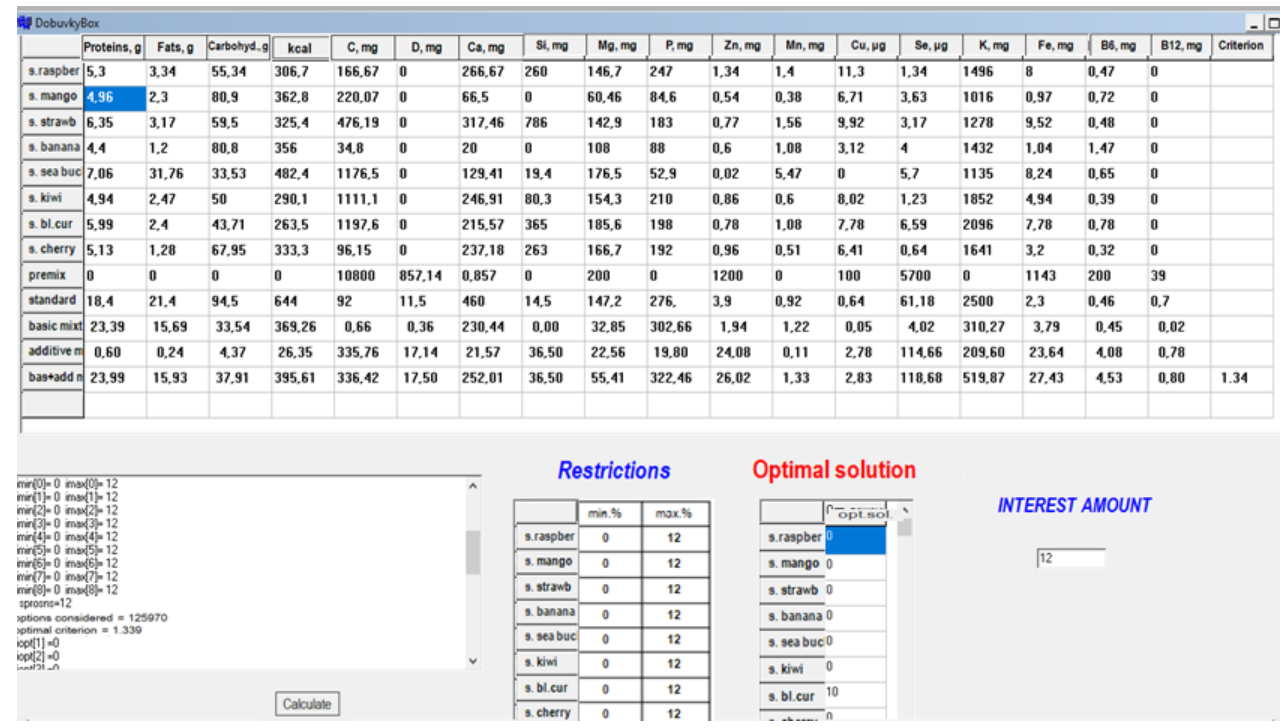

Fig. 2. Interface and result of solving the optimization problem with additional raw materials.

The developed algorithm leads to obtaining a solution and ensuring the most optimal values of nutrients in the composition of the food mixture according to a given standard.

Table 1. Chemical composition of the designed food mixture.

\begin{tabular}{|c|c|c|}
\hline Food ingredients & Reference & Engineered food blend sample \\
\hline \multicolumn{3}{|c|}{ Energy value and macronutrients } \\
\hline EC, $\mathrm{kcal}$ & 644 & 395,61 \\
\hline Proteins, $\mathrm{g}$ & 18,4 & 23,99 \\
\hline Fats, g & 21,4 & 15,93 \\
\hline Carbohydrates, g & 94,5 & 37,91 \\
\hline \multicolumn{3}{|c|}{ Minerals } \\
\hline $\mathrm{Ca}, \mathrm{mg}$ & 460,0 & 506,83 \\
\hline $\mathrm{Fe}, \mathrm{mg}$ & 2,3 & 27,43 \\
\hline $\mathrm{P}, \mathrm{mg}$ & 276,0 & 322,46 \\
\hline $\mathrm{Mg}, \mathrm{mg}$ & 147,2 & 55,41 \\
\hline $\mathrm{Se}, \mu \mathrm{g}$ & 61,18 & 118,68 \\
\hline $\mathrm{Zn}, \mathrm{mg}$ & 3,8 & 26,02 \\
\hline $\mathrm{Si}, \mathrm{mg}$ & 14,5 & 36,50 \\
\hline $\mathrm{Cu}, \mathrm{mg}$ & 0,64 & 2,83 \\
\hline $\mathrm{K}, \mathrm{mg}$ & 575,0 & 519,87 \\
\hline $\mathrm{Mn}, \mathrm{mg}$ & 0,92 & 1,33 \\
\hline \multicolumn{2}{|c|}{ Vitamins } \\
\hline $\mathrm{D}_{3}, \mu \mathrm{g}$ & 11,5 & 17,5 \\
\hline $\mathrm{C}, \mathrm{mg}$ & 92,0 & 4,53 \\
\hline $\mathrm{B}_{6}, \mathrm{mg}$ & 0,46 & 0,8 \\
\hline $\mathrm{B}_{12}, \mu \mathrm{g}$ & 0,69 & \\
\hline
\end{tabular}

The data in Table 1 made it possible to select the ratio of the components of the designed food mixture that most satisfies the requirements that should be used in the development of food for people with a predisposition to impaired bone mineral density. One serving of the food mixture meets the recommended nutritional composition with a single meal in the following quantities: for calcium $-110 \%$, for selenium - $194 \%$, for silicon - $251 \%$, for phosphorus - $117 \%$, for manganese $-149 \%$ and for vitamin $D_{3}-152 \%$. The 
amounts of the above-mentioned nutrients exceed the average daily intake for ordinary people [9], but taking into account the orientation of the developed mixture to a group of consumers with a predisposition to BMD impairment, the norms for these nutrients were increased to achieve a rationally balanced blend of the food mixture. However, the average daily maximum permissible concentration does not exceed the established norms for the corresponding nutrients [10].

Thus, the designed mixtures can be recommended for people with a predisposition to diseases associated with impaired bone mineral density.

\section{Conclusions}

The developed program for designing the composition of food mixtures allows, within the framework of the accepted restrictions on the content of the main and additional raw materials in the mixture, to obtain a rational ratio in the amount of vitamins and minerals, according to a given standard. The interface of the developed program also displays data on the ratio of the ingredients introduced, taking into account the specified parameters.

Thus, the application of this program will allow technologists at public catering enterprises to more comprehensively approach the development of the recipe composition of individual products and the diet as a whole.

\section{Acknowledgements}

This study was funded with the support of the Russian Foundation for Basic Research, project № 20-316-90043.

\section{References}

1. Sidorenko Yu. I., Nikitin I. A., Khairullin M. F. and Sidorenko M. Yu., Trends in food technology transformation in the context of globalization Bread products, 1, 44-48 (2020)

2. Nikitina M. A., Nikitin I. A., Semenkina N. G., Zavalishin I. V. and Goncharov A.V., Application of the hierarchy analysis method at the foodstuffs quality evaluation International Journal of Advanced Computer Science and Applications, 9 (5), 51-59 (2018)

3. Dibrova Zh. N., Nosov V. V., Ovchenkova G. S., Karpenko E. Z., Pilyugina A. V. and Erkovich E. A., The main directions of the solution of the problem of food security in Russia International Journal of Mechanical Engineering and Technology, 9 (12), 387-394 (2018)

4. Zhichkin K., Nosov V., Zhichkina L., Zhenzhebir V. and Rubtsova S., The agricultural crops production profitability in modern conditions E3S Web of Conferences, 175 (2020)

5. Kunakova R. V., Zainullin R. A., Khusnutdinova E. K. and Yalaev B. I., Healthy nutrition of the XXI century: functional food and nutrigenomics Bulletin of the Academy of Sciences of the Republic of Bashkortostan, 21 (3), 5-14 (2016)

6. Ferguson L. R., Nutrigenomics approaches to functional foods J Am Diet Assoc, 109, 452-458 (2009)

7. Müller M. and Kersten S., Opinion: Nutrigenomics: goals and strategies Nature Reviews Genetics, 4, 315-322 (2003) 
8. Ivanova V. N., Nikitin I. A., Zhuchenko N. A., Nikitin M. A., Sidorenko Yu. I., Karpov V. I. and Zavalishin I. V., Clustering of multidimensional objects in the formation of personalized diets International Journal of Advanced Computer Science and Applications, 10 (2), 45-50 (2019)

9. Karpov V. I. and Portnov N. M., Optimization of the recipe composition of the food product Conference materials System analysis in design and management, 169-182 (2020)

10. Methodical recommendations MR 2.3.1.2432-08. Norms of physiological energy and nutrient requirements for various groups of population of the Russian Federation 